\title{
Effectiveness of an Animation Video on Behavioral Response to Pain among Toddlers During Immunization in a Selected PHC at Mangalore India
}

\author{
Bijimol N.J. ${ }^{1}$, Shycil Mathew ${ }^{2}$ \\ ${ }^{1}$ M.Sc. Nursing, Lecturer Dept. of Community Health Nursing, St. Johns's college of Nursing Koramangala, \\ Bangalore, ${ }^{2}$ Lecturer Department of Community Health Nursing, Yenepoya Nursing College, Yenepoya (Deemed to \\ be University), Deralakatte, Mangaluru, Karnataka, India
}

\begin{abstract}
Background: Immunization is regarded as one of the most significant medical achievements of all times. Recently, increasing attention has been paid to the pain resulting from routine childhood immunizations. In addition, lack of adequate pain management during immunization exposes children to unnecessary suffering and the potential for long-term consequences, such as fear of needles. Hence this study is intended to assess the Effectiveness of an Animation Video On behavioral Response to Pain among Toddlers during Immunization.
\end{abstract}

Materials and Method: A quasi-experimental research (non-equivalent post-test-only control group) design was used for this study. The sample was drawn through purposive sampling technique and comprised of 60 toddlers undergoing for immunization (30 in experimental and 30 in control group) in a selected PHC at Mangalore, India. Data was collected using Behavioral response assessment scale to pain. (Modified FLACC behavioral assessment scale).

Results: Majority of the toddlers in Group I (83.33\%) were having moderate behavioural response to pain, only $16.7 \%$ were having severe behavioural response to pain whereas in Group II (100\%) all the toddlers experienced severe behavioural response to pain during immunisation. The mean score of behavioural response to pain of Group II (10.97 \pm 1.69$)$ was greater than that of Group I ( $7.17 \pm 1.206)$.

Conclusion: An animation video during immunization can be an effective, simple, non-invasive, and cost effective diversional technique had a positive effect on children's distress behaviour and pain and having no side effects on the toddlers.

Keywords: Animation video, immunization, behavioral response, pain, toddlers.

\section{Introduction}

Prevention of disease is one of the most important

\section{Correspondence Author:}

\section{Ms. Shycil Mathew}

M.Sc. Nursing, Department of Community Health

Nursing, Yenepoya Nursing College, Yenepoya

(Deemed to be University), Deralakatte, Mangaluru,

Karnataka-575018

e-mail: shycilplakkattu7070@gmail.com

Contact Address: 9538812499 goals in child care. During infancy and childhood, preventive measures against certain infectious diseases are available. Immunization is an important and cost effective public health tool for disease control ${ }^{(1)}$ Routine immunization injections are the most common painful procedures in childhood. Most of the immunizations are administered early in a child's life. Most toddlers and many school-age children experience high distress during immunization injections ${ }^{(2)}$.

Untreated immunization pain might also lead to distorted negative memories of that experience. 
Ultimately, early pain is linked to poorer healthcare attitudes and elevated fear and avoidance of medical procedures in adulthood $^{(3)}$. The child's distress is upsetting not only for the child but also for the adults involved-both parents and professionals-and it often makes it more difficult to complete the needed procedure $^{(4)}$.

Non-pharmacological method of pain control are widely accepted and can be used with or without analgesics ${ }^{(5)}$. A cardinal responsibility of a community health nurse taking part in giving immunisation is to alleviate pain, promote growth, and development of child $^{(6)}$.

Aim: To assess the Effectiveness of an Animation Video On behavioral Response to Pain among Toddlers during Immunization.

\section{Objectives of the Study:}

1. To determine the behaviour response to pain among toddlers receiving immunisation with animation video (Group I) as measured by structured behavioural response assessment scale to pain (modified FLACC behavioural assessment scale).

2. To identify the behaviour response to pain among toddlers receiving immunisation without animation video (Group II) as measured by structured behavioural response assessment scale to pain.

3. To compare the effectiveness of animation video on behavioural response to pain among toddlers in Group I and in Group II during immunisation.

4. To find the association between behavioural response to pain among toddlers receiving immunisation in Group I and in Group II with their selected demographic variables.

\section{Materials and Method}

Study setting and sample size: A quasiexperimental research (non-equivalent post-test-only control group) design was used for this study. The sample was drawn through purposive sampling technique and comprised of 60 toddlers undergoing for immunization (30 in experimental and 30 in control group) in a selected PHC at Mangalore India .The parents were interviewed on the basis of baseline proforma. The child along with the caregiver was taken to the treatment room. In experimental group (Group I) the investigator made the parent sit on the chair comfortably with the child on the lap and showed the animation video. In control group (Group II) the children were placed in position and restrained by the nurse or parent as routine practice of the clinic.

The behaviours of the subjects were observed by the investigator in three phases during the procedure, i.e., placing the child in position, pre immunisation, and actual procedure until the child is out of the immunisation room. The investigator observed and scored the child's behavioural response to pain during immunisation injection using the behavioural response assessment scale to pain. Data was collected using behavioral response assessment scale to pain. (Modified FLACC behavioural assessment scale).

Data Analysis: The data was collected after obtaining prior permission from the concerned authority to conduct the study. The participants were assured about the confidentiality of their responses. The data was analyzed in terms of objectives of the study using both descriptive and inferential statistics. The data obtained was plotted in the master sheet.

\section{Findings:}

\section{Results}

\section{Section I: Description of baseline proforma}

- Majority (83.3\%) of the samples were between 1218 months of age.

- Majority (63.3\%) of the samples were male.

- All (100\%) of the children were undergoing DPT immunisation.

- Highest percentage (46.7\%) of the children showed minimal resistance to previous immunisation.

- Majority (56.7\%) of children had more than $10 \mathrm{~kg}$ of weight at the time of immunisation.

Section II: Description of level of behavioural response to pain among toddlers during immunisation procedure in Group I: The areawise mean percentage shows that the behavioural response to pain was more in the areas arms (mean percentage $=66.67 \%)$ legs (mean percentage $=65.00 \%$ ), and restlessness (mean percentage $=65.00 \%$ ). There was less behavioural response to pain in the areas like muscle tone (mean percentage $=63.33$ ) cry and vocalisation (mean percentage $=58.33 \%$ ) and facial expression (mean percentage $=41.67$ ), in the Group I. [Table-1]. 
Section III. Description of level of behavioural response to pain among toddlers during immunisation procedure in Group II.

The area wise behavioural response to pain in Group II was more in the areas of arms, muscle tone, and restlessness (mean percentage $=96.67 \%$ ) cry and vocalisation (mean percentage $=95 \%$ ) leg (mean percentage $=88.33 \%$ ), and facial expression (mean percent $=71.67 \%$ ). [Table-II]

Section IV. Comparison between level of behavioural response to pain scores in Group I and Group II

The majority of the toddlers in Group I (83.33\%) are having moderate behavioural response to pain, only $16.7 \%$ are having severe Behavioural response to pain whereas in Group II all toddlers (100\%) experienced severe behavioural response to pain during immunisation. [Figure-1].
Section V: Significant difference between level of behavioural response to pain among toddlers during immunisation injection in Group and Group II

Significant difference between level ofbehavioural response of pain in Group I and Group II showed that Group II has severe behavioural response than Group I $(10.97 \pm .928 \mathrm{~V} / \mathrm{S} 7.17 \pm 1.206)$. The calculated value $(t=13.680, p<0.001)$ indicates the significant difference between the behavioural response scores between the two groups. [Table-III].

Section VI: Association of level of behavioural response to pain among toddlers in Group I and Group II with their selected demographic variables

The behavioral response to pain among toddlers in Group I and Group II with their selected demographic variables shows no significant association at 0.05 level of significance. [Table-IV].

Table-I: Description of level of behavioural response to pain among toddlers during immunisation procedure in Group I. $\mathbf{N}_{1}=30$

\begin{tabular}{|l|c|c|c|c|c|}
\hline \multicolumn{3}{|c|}{} & \multicolumn{3}{c|}{ Group I } \\
\hline Item & Max. Possible Score & Range & Mean & SD & Mean \% \\
\hline Facial Expression & 2 & $0-2$ & .83 & .379 & 41.67 \\
\hline Arms & 2 & $0-2$ & 1.30 & .466 & 65.00 \\
\hline Legs & 2 & $0-2$ & 1.33 & .479 & 66.67 \\
\hline Cry \& Vocalization & 2 & $0-2$ & 1.17 & .379 & 58.33 \\
\hline Muscle Tone & 2 & $0-2$ & 1.27 & .450 & 63.33 \\
\hline
\end{tabular}

Table-II Description of level of behavioural response to pain among toddlers during immunisation procedure in Group II. $\mathbf{N}_{2}=30$

\begin{tabular}{|l|c|c|c|c|c|}
\hline \multicolumn{2}{|c|}{} & \multicolumn{3}{c|}{ Group II } \\
\hline Item & Max. Possible Score & Range & Mean & SD & Mean \% \\
\hline Facial Expression & 2 & $0-2$ & 1.43 & .507 & 71.67 \\
\hline Arms & 2 & $0-2$ & 1.77 & .430 & 88.33 \\
\hline Legs & 2 & $0-2$ & 1.93 & .254 & 96.67 \\
\hline Cry \& Vocalization & 2 & $0-2$ & 1.90 & .305 & 95.00 \\
\hline Muscle Tone & 2 & $0-2$ & 1.93 & .254 & 96.67 \\
\hline Restlessness & 2 & $0-2$ & 1.93 & .254 & 96.67 \\
\hline
\end{tabular}


Figure 1 Comparison of level of behavioural response to pain among toddlers during immunisation procedure in Group I and Group II.

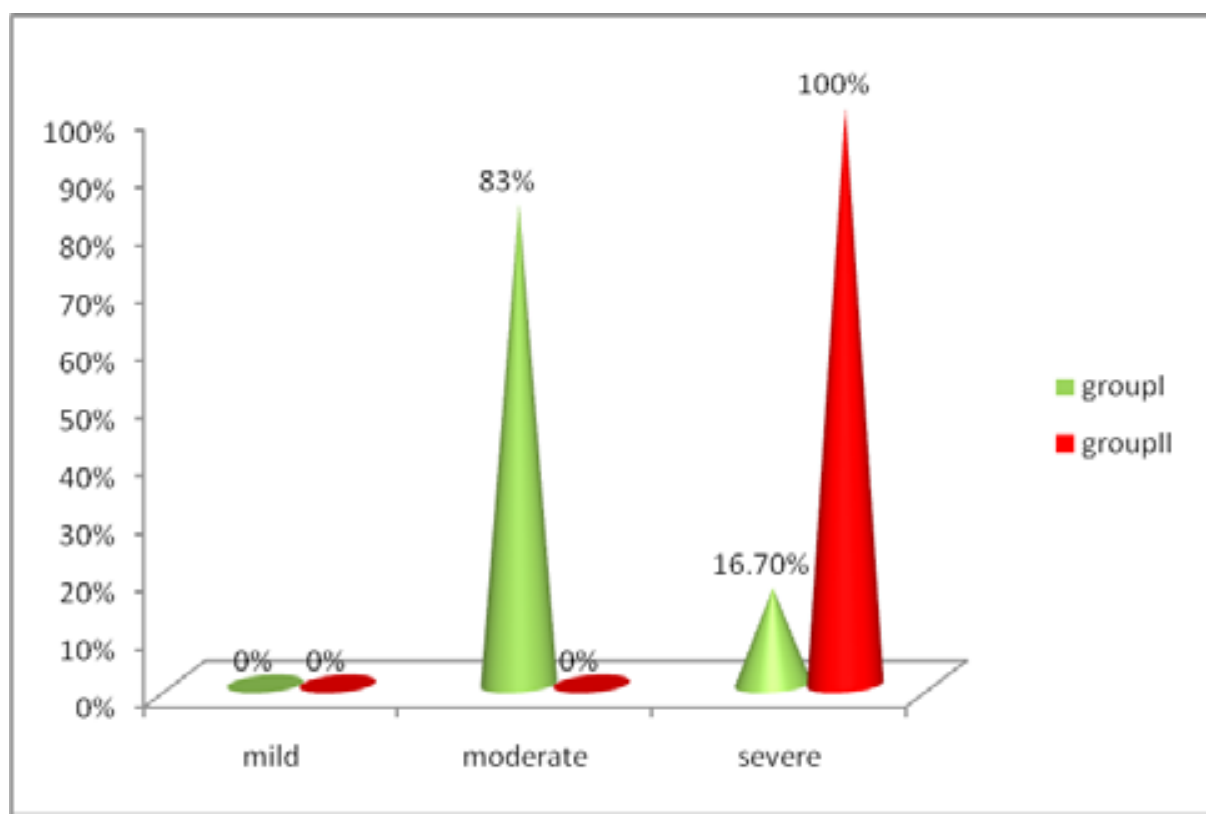

Figure 1: Level of behavioral response to pain among toddlers in Group I and Group II

Table III: Significant difference between level of behavioural response to pain scores in Group I and Group II. N=30+30

\begin{tabular}{|l|c|c|c|c|}
\hline Gruop & Mean & SD & Mean diff & 't' value \\
\hline Group I & 7.17 & 1.206 & \multirow{2}{*}{3.800} & 13.680 \\
\hline Group II & 10.97 & 0.928 & & \\
\hline
\end{tabular}

$\mathrm{T}_{59}=1.67$ * significant.

Table IV: Association of level of behavioural response to pain among toddlers in Group I and Group II with their selected demographic variables

\begin{tabular}{|c|c|c|c|c|c|c|}
\hline \multirow{2}{*}{ Variables } & \multicolumn{3}{|c|}{ Group I (\%) } & \multicolumn{3}{|c|}{ Group II (\%) } \\
\hline & $<\mathbf{M}$ & $\geq \mathbf{M}$ & P value & $<\mathbf{M}$ & $\geq \mathbf{M}$ & P value \\
\hline \multicolumn{7}{|l|}{ Age of the Child } \\
\hline a. $12-18$ months & 25.9 & 74.1 & \multirow{4}{*}{1.00} & 39.1 & 60.9 & \multirow{4}{*}{$0.057^{*}$} \\
\hline b. 19-24 months & 33.3 & 66.7 & & 0.0 & 100.0 & \\
\hline c. $25-30$ months & 0.0 & 0.0 & & 0.0 & 0.0 & \\
\hline d. 31-36 months & 0.0 & 0.0 & & 0.0 & 0.0 & \\
\hline \multicolumn{7}{|l|}{ Gender } \\
\hline a. Male & 31.6 & 64.8 & \multirow{2}{*}{0.710} & 31.6 & 68.6 & \multirow{2}{*}{1.00} \\
\hline b. Female & 18.2 & 81.8 & & 27.3 & 72.7 & \\
\hline \multicolumn{7}{|c|}{ Child's Recent Past Experience } \\
\hline a. High resistance & 0.0 & 100.0 & \multirow{3}{*}{$0.055^{*}$} & 22.2 & 77.8 & \multirow{3}{*}{0.057} \\
\hline b. Minimal resistance & 36.4 & 63.6 & & 33.3 & 37.7 & \\
\hline c. Calm & 36.4 & 63.6 & & 33.3 & 67.7 & \\
\hline \multicolumn{7}{|c|}{ Weight of the Child at the Time of Immunization } \\
\hline
\end{tabular}




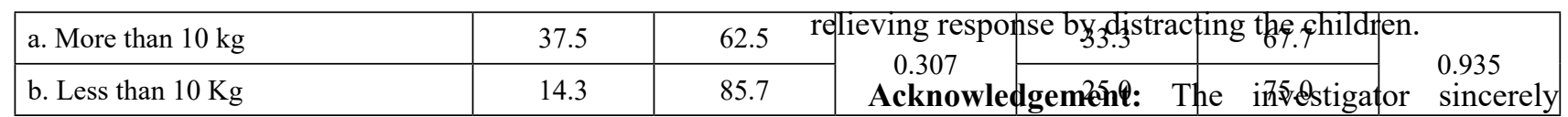

*Fisher's Exact test

\section{Discussion}

The present study revealed that the behavioral response to pain among toddlers during immunization procedure in Group I and Group II showed that, the Group I had moderate behavioral response to pain $(83.3 \%)$ and $16.7 \%$ had severe behavioral response to pain while undergoing immunization, whereas Group II had severe pain (100\%) during the immunization.

The above findings are consistent with a quasi experimental study conducted at pediatric surgery ward (6th floor, C block) of Advanced Pediatric Centre (APC), PGIMER, Chandigarh by James Jet al (2012) The mean pain score was significantly less i.e. almost half with animated cartoon $(2.26 \pm 2.18)$ as compared to routine care $(4.76 \pm 2.08)$ at pre venipuncture. Similarly the mean pain score during venipuncture was significantly less with animated cartoon $(6.24 \pm 2.09)$ as compared to routine care $(8.06 \pm 1.70)^{(19)}$

The present study findings showed that there is no association between level of pain among toddlers in Group I and Group II and selected demographic variables (Fisher exact test, $\mathrm{p}>0.05$ ).

The above findings are consistent with a quasiexperimental study was conducted on children of 3 to 6 years of age who were undergoing venipuncture in selected hospitals of Mangalore by MM Lobo and Umarani $j$ (2012). The findings also revealed that there was no significant association between the level of pain and demographic variables ${ }^{(20)}$.

\section{Conclusion}

Present study findings showed that, Distraction techniques like showing the animation video during immunizations are effective means for reduction of behavioural response to pain. It can also be used as a routine with immunisation so that children's behavioural distress can be managed in an effective way. The study concluded that animation video is effective on behavioural response to pain in children receiving immunisation. It is important for the nurses, who administer immunisation, to alter the painful responses as much as possible. Nurses must meet the challenges in acknowledges the support given by Mrs. Shycil Mathew and Shanti Lobo for their timely support and smart guidance to complete the project. Sincere gratitude towards the study participants for their cooperation.

Financial support and sponsorship: Nil.

Conflicts of Interest: There are no conflicts of interest.

Ethical Clearance: Written informed consent was obtained from the parents of the children who brought their children for immunization at PHC. Ethical clearance was obtained from institutional ethics committee of CHCT, Mangalore.

\section{Reference}

1. Malathy S. Mothers knowledge on growth and development of their children between 0-3 years in selected rural area. Indian Journal of Nursing 2012 Jul;1(1):56-60.

2. Singh P. Assess the comparitive effect of distraction techniques in behavioural response to pain among toddlers during immunisation: The Nursing Journal of India 2012 Jul;1(1):176-9.

3. Emine E, Zeynep EC. The use of breastfeeding for pain relief during neonatal immunisation injection. Applied Nursing Research 2007;20:10.

4. Nath B, Singh JV, Awasthi S. Client satisfaction with immunisation services in urban slums of Lucknow district. Indian Journal of Paediatrics 2009;76.

5. Agras S, Sylvester D, Oliveau D. The epidemiology of common fears and phobias. Comprehensive Psychiatry 1996;10:1151-6.

6. Stevens B, Johnson C. Premature infant pain profile: development and initial validation. Journal of Paediatric Nursing 1996;12:13-22.

7. McCarthy AM, Kleiber C. A conceptual model of factors influencing children's responses to a painful procedure when parents are distraction coaches. Journal of Paediatric Nursing 2006;21(2):88-96.

8. Bowen AM, Dammeyer MM. Reducing children's immunisation distress in a primary care setting. Journal of Paediatric Nursing 1999;14(5):296.

9. Simons J, Frank L, Roberson E. Parent involvement 
in children's pain care: views of parents and nurses. Journal of Advanced Nursing 2001;36(4):591-9.

10. Breau ML, McGrath JP, Craig KD. Facial expression of children receiving immunisations: A principal components analysis of the child facial coding system. The Clinical Journal of Pain 2001;17:178-86. 1.

11. Fanurik D, Koh JL, Harrison RD. Pain assessment in children with cognitive impairment; an exploration of self-report skills. Clinical Nursing Research 1998;7:103-24.

12. McGrath PJ, Rosmus C, Camfield C. Behaviours caregivers use to determine pain in non-verbal, cognitively impaired individuals. Dev Med Child Neuro 1998;40:340-43.

13. Beyer JE, McGrath PJ, Berde CB. Discordance between self-report and behavioural pain measures in children aged 3-7 years after surgery. J Pain Symptom Management 1997;5:350-56.

14. Stanford EA, Chambers CT, Craig KD. Ow!: spontaneous verbal pain expression among young children during immunisation. Clinical Journal of Pain 2005;21(60).

15. Ipp M, Taddio A, Sam J. Vaccine related pain: randomised controlled trail of two injection techniques. Archives of Disease in Childhood 2007;92:1105.

16. Colleen LM, Finkelstein M, Thygeson MV. The impact of animation video on fear, during immunisations:. Journal of Paediatric Nursing 2008;23(3):195-200.

17. Gedam DS, Verma M, Patel U, Gedam S. Effect of distraction technique during immunization to reduce behaviour response score (FLACC) to pain in toddlers. Journal of Nepal Paediatric Society. 2013 Jun 15;33(1):25-30

18. Cohen LL, Blount RL, Panopoulos G. Nurse coaching and cartoon distraction: An efective and practical intervention to reduce child, parent, and nurse distress during immunizations. Journal of Pediatric Psychology. 1997 Jun 1;22(3):355-70.

19. James J, Ghai S, Rao KL, Sharma N. Effectiveness of" Animated Cartoons" as a distraction strategy on behavioural response to pain perception among children undergoing venipuncture. Nursing and Midwifery Research Journal. 2012 Jul;8(3):198207.

20. Lobo MM, Umarani J. Cartoon Distraction Reduces Venipuncture Pain among Preschoolers-a Quasi Experimental Study. Medical Science. 2013 Jun;2(6). 